\title{
Anatomia do lenho secundário de Annona glabra L. (Annonaceae), algumas propriedades físicas da madeira e análise crítica da grafia do gênero
}

\author{
Ezechias Paulo Heringer (") \\ José Elias de Paula (")
}

\section{Resumo}

Analisadas a estrutura do lenho secundário da raiz, da madeira e silgumas de suas propriedades físicas, bem como a estrutura da casca. Foram realizados testes histoquímicos para detectar elementos minerais ocorrentes na madeira e na casca. $\mathrm{Pa}$ ralelamente estabelecida, através de pesquisas bibliográficas, a grafia correta do gênero Annona.

\section{INTRODUÇÃO}

A grafia da palavra Annona vem sendo usada sem um critério uniforme, tanto no Brasil como no exterior. Alguns autores empregam Anona, outros Annona e, finalmente, outros usam as duas formas.

Fazendo-se uma análise histórica do uso da palavra por botânicos notáveis, nacionais e estrangeiros, imaginamos que as duas grandes obras clássicas de Botânica manuseadas diariamente por quem trabalha com Sistemática Vegetal têm influído para que se estabelecessem os dois grupos. Referimo-nos a Flora Brasiliensis que usa Anona e o Index Kewensis que grafa Annona. Mencionamos a seguir alguns autores que usam a grafia Anona.

Lofgren \& Everett (1913) em Estudo Botânico do Nordeste-VIII citam Anona palustris; Ferri (1944) emprega Anona coriacea em seu trabalho sobre transpiração de plantas permanentes do cerrado; Freire (1943) em "Chaves Analíticas" escreve Anonaceae e oferece duas origens para a palavra; Ducke (1917) em "Plantas novelles ou peu connues de la région amazonienne", grafa Anona, Anonaceae; Hoehne, Kuhlmann \& Handro (1941) em o "Jardim Botânico de Sã̃o Paulo" empregam Anonáceas, Anona cacans; Schultze (1963) na introduẹão ao estudo da Botânica Sistemática escreve Anona Salzmanii, Anona palustris;
Kuhlmann (1925) em "Contribuição para o conhecimento de algumas plantas novas", contendo também um trabalho de crítica a rovas combinações, escreve: in ramis Anonae palus. tris; Heringer (1955) em Diagnose do fruto de Anona pygmaea.

Alguns autores estrangeiros que usam a grafia Anona: Gray (1908) em "Manual Bota. ny" emprega Anonaceae; Gilg (1926) em "Botânica Aplicada à Farmácia" grafa Anona muricata; Record \& Hess (1949) em "Timbers of the New World" empregam Anonae, Anona (Annona), citando para o Sudeste da Flórida a Anona glabra L. que forma densa floresta nos brejos próximos à costa Atlântica. Salienta ainda que a madeira de Anona glabra é tão leve que é usada localmente como substituto da cortiça para flutuadores de redes de pesca e protetores de ancoragem. Cobley (1957) em "The Botany of Tropical Crops", informa: 'Anonaceus fruits", Anona muricata "Sour sop". Anona reticulata Bulbook's; Fries (1931) em "Revision der Arten liniger Anonaceen", em. prega Anona.

Autores que empregam Annona: Erdtman (1952) "Pollen morfology and Plants Taxonomy" usa Annona tripeltata; Heringer \& Barroso (1968) em "Sucessão das espécies do cerrado em função do fogo, cupim e cultivo", usam Annona pygmaea, Annona crassiflora; Metca!fe \& Chalk (1957) em "Anatomy of Dicatyledons", escrevem Annona glauca; Rizzin! (1963) grafa Annona coriacea, Annona crassiflora, em "A Flora do Cerrado"; Santos (1963) em "Nomes vernáculos de algumas plantas da Guiné Portuguesa" escreve Annona glabra; Souza (1960) em "Estudos, Ensaios e Documentação" grafa Annonaceae e cita Annona glauc: da Praia Varela, como sinônimo de Annona pa lustris. O Index Genericorum, aceita o gêne-

(*) - Universidade de Brasília, D.F. 
ro com a grafia Annona como sendo de 1853. mas não decide pela forma do $n n$ empregado na grafia de Annona, por Linnaeus, deixando em alternativa.

Esta palavra de origem romana que significava na mitologia daquele povo a personificação da abundância de frutos, de espiga de grãos simbolizados pela cornucópia ou ainda significava produção agrícola de um ano, escrevia-se Annona; Linnaeus baseou-se neste vocábulo para batizar o seu gênero Annona, homenageando a mitologia da Roma Antiga.

Finalmente deve-se grafar Annona Linnaeus, conforme estabelece o Código Internacional de Botânica e Nomenclatura de 1972 que mantém em "nomina conservanda" esta grafia.

Annona é um gênero da América Tropical em que se distribui com aproximadamente 100 espécies (Record \& Hess, 1949), ocorrendo da Flórida, América Central, Amazonia e até América Subtropical. As espécies, em gerai se caracterizam pelo valor alimentício dos irutos suculentos, tanto para a fauna nativa come para o homem da selva e como do civilizado.

Segundo Record \& Hess (1949), uma das espécies mais conhecidas é Annona glabra L., árvore que alcança até 12 metros de aitura, fuste curto, com $35 \mathrm{~cm}$ de diầmetro. Na Flórida forma freqüentemente densas matas, nos terrenos inundáveis, próximos da costa. As raízes, muito leves e esponjosas são usadas com freqüência, para substituir a cortiça nas boias de redes de pescar.

No cerrado, duas espécies do gênero Annona participam da paisagem desta flora: Annona coriacea e Annona crassiflora. Parece-nos aceitável que se trata neste trabalho de Annona glabra L. (= Annona palustris L.) posta em sinonímia daquela por Fries (1931). Os coletores nunca fizeram referência a habitat paludícula da Annona Salzmannii A. DC. As referências sobre a espécie encontrada nas fichas de herbários, são: árvore com co pa rámosíssima, tronco crasso e altura medíocre, o que não ocorrem em Annona glabra L. que é árvore de 10 metros de altura, com larga disperøão, pelo México, Colômbia, Flórida, Cuba, Jamaica, Porto Rico, Venezuela, África, e no Brasil, desde a Amazônia, passando pelo Nordeste até Santa Catarina. Forma po- pulações densas que a torna explotável pelos pescadores da Flórida, referência feita po: Record \& Hess (1949). O emprego das raizes se faz ao mesmo tempo no Nordeste do Brasil como na Flórida. No Brasil, Annona glabra ocorre com muita freqüência nas áreas estuarinas, notadamente nas inundadas por água doce e salgada; seus frutos são bastante apreciacios.

\section{MATERIAL E MÉTODO}

O material que serviu de confirmação da espécie encontra-se depositado no herbário da Universidade de Brasília (UB) com as informações seguintes: Heringer et Paula, 12.778, em 20-1-973, Porto de Galinha- Pernambuco.

$\mathrm{O}$ oxalato e o carbonato foram identificados com ácido sulfúrico a $50 \%$. A sílica foi detectada pela sua solubilidade no ácido fluo. rídrico, na proporção de $1 / 2$ de água destilada (Molisch, 1923) e pela insolubilidade nos demais ácidos.

\section{Resultados}

\section{RAíz (fotos 1 a 10)}

Caracteres gerais. Raiz grossa, até $25 \mathrm{~cm}$ de diâmetro extremamente leve, peso específico $0,099 \mathrm{~g} / \mathrm{cm}^{3}$, semelhante a cortiça, queimandose com dificuldade; textura extremamente fina; cor alvacenta, sendo que a parte mais central é um pouco escura; casca fina, rica em óleo essencial.

Caracteres macroscópicos (foto 1). Estrutura com aspecto esponjoso; poros indistintos, mesmo com auxílio de lupa; raios pouco perceptíveis com lupa; camadas de crescimento indistintas devido a estrutura peculiar do parênquima; fibras ausentes.

Caracteres microscópicos. Vasos, escassos. Poros (fotos 2 a 4): solitários, geminados e múltiplos radiais de 3 a 4 ou agrupados de 3 a 5 . Nas raizes mais espessas observamos somente poros na porção mais externa, isto é, próximo do câmbio (foto 2), pois, na parte mais central, o contorno das paredes dos elementos traqueais se deformam e em conseqüência são semelhantes às células parenquimatosas, vistos em corte transversal (fotos 2 e 3 ). Os poros são pequenos, entre 40 

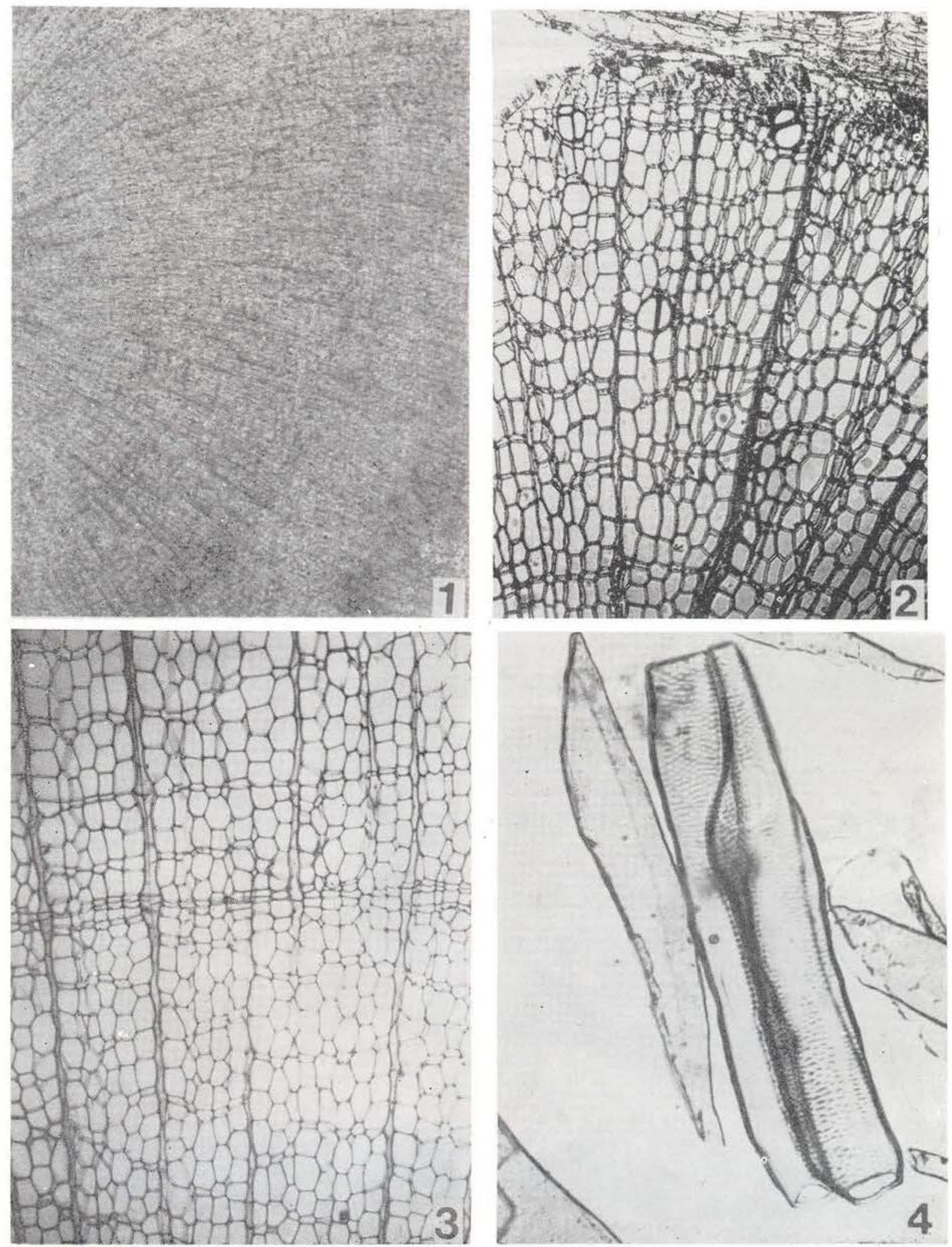

Raiz: Foto 1 - Aspecto macroscópico da raiz (12x); Foto 2 - Corte transversal de uma raiz relativamente grossa $(130 \mathrm{x})$ ao nível do câmbio; Foto 3 - Corte de uma raiz relativamente grossa, na porção mais central (80x); Foto 4 - Elementos dissociados $(270 \mathrm{x})$. 

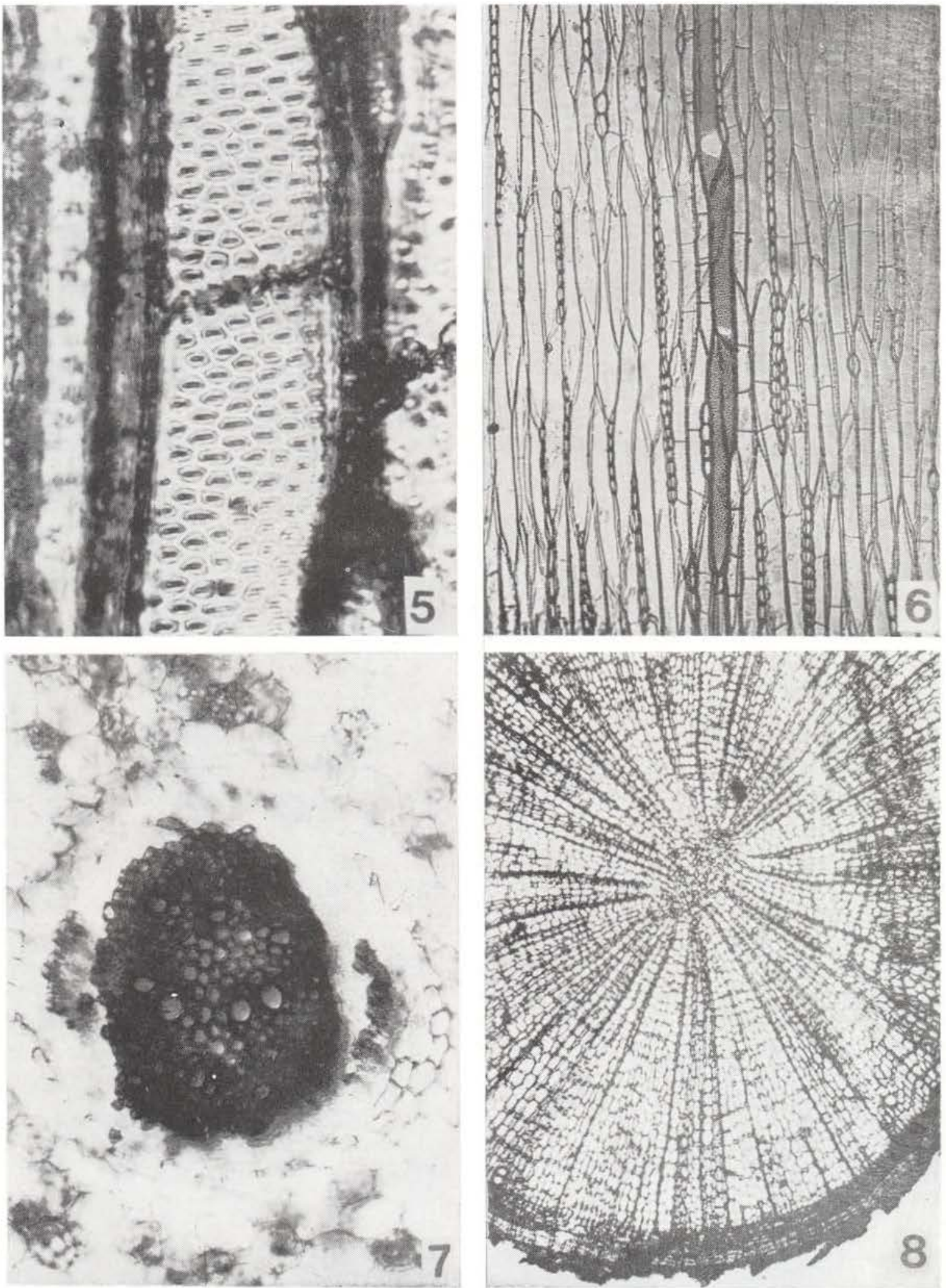

Raiz: Foto 5 - Pontuações intervasculares da raiz $(600 \mathrm{x})$; Foto 6 - Corte tangencial da raiz (80x); Foto 7 - Estrutura primária da raiz $(60 \mathrm{x})$; Foto 8 - Estrutura secundária de uma raiz fina $(73 \mathrm{x})$. 
a $47 \mu \mathrm{m}$ de diâmetro. Os elementos traqueais são curtos e estreitos, com placa de perfuração simples, parcial ou total (foto 4). Pontuacões intervasculares (foto 5): pares de pontuaçōes areolados, numerosos, de disposição alterna, pontuações com abertura estreita, inclusa, raramente exclusa. Raios (foto 6) heterogêneos, tipo II de Kribs, de 1 a 2 seriados, não havendo predominância de nenhum deles; alguns raios bisseriados possuem as porções unisseriadas bastante longas, enquanto que noutros, as porções unisseriadas são curtas, ocorrem também raios com apenas uma extremidade unisseriada e raios uniformes. Os raios são constituídos de 3 a 46 células de altura. sencio mais freqüentes entre 18 e 28 ; pouco numerosos a numerosos entre 6 e 10 raios por milímetro, sendo mais freqüentes entre 8 e 10 (numercsos); muito baixos, $0,65 \mathrm{~mm}$ de altura em média variando entre 0,35 e 0,99 , sendo $60 \%$ entre 0,42 e 0,63 ; as células radiais são ricas em grãos de amilo e possuem paredes bastante finas, pouco lignificadas. Parênquima (fotos 2 e 3): representa a maior parte do conteúdo de tecido que constitui a raiz. É um parênquima aerifero e caracteristicamente semelhante ao parênquima fundamental de estrutura primária de caule e raiz. Consta de células de contorno e diâmetro variados, vistas em corte transversal; com paredes bastante finas, ricas em pontuaçōes, quase carentes de lignina e deixam entre si espaços intercelulares; vistas dissociadas, em material macerado, elas são largas e moderadamente alongadas, semelhantes aos elementos dos vasos, habitualmente com extremidades obtusas. Neste parênquima, as células amilíferas são pequenas em comparação com as demais e se dispõem tangencialmente. Fibras ausentes. A raiz de espécime jovem tem estrutura primária típica de raiz normal, com vários polos de protoxilema, e parênquima central (foto 7). A foto 8 ilustra uma raiz fina de estrutura secundária, em corte transversal.

Casca (fotos 9 e 10). Apesar da palavra casca não ser um nome técnico, preferimos usá-lă invés de córtex, para melhor compreendermos todos os tecidos que ficam por fora do cilindro lenhoso das árvores e das raizes idosas, tendo em vista que, o termo córtex tem sido usado, tanto para o período de crescimento primário como para o secundário.

Consideramos aqui, duas partes da casca: द) casca externa, ritidoma), casca morta (foto 9) é o tecido formado para o exterior. pelo felogênio. A referida casca é constituída somente de um tipo de céluias: as suberosas típicas. b) casca interna (foto 9) é a casca viva, representada por células parenquimatosas com paredes pectocelulósicas, de fibras floemáticas de paredes espessas e de raios 3 a 5 seriados, cujas células possuem paredes finas, pectocelulósicas. Aqui a casca interna em apreço é formada pelo câmbio e está compreendida entre o felogênio e a zona cambial (foto 9). São freqüentes na casca viva, "glândulas" com gotículas de óleo graxo e essencial (foto 10), ao lado de outras, ricas em grãos de amilo. As iniciais fusiformes não formam fibras libriformes, somente flot máticas, não formando portanto, fibras no xilema.

\section{MADEIRA (fotos 11 a 17)}

Caracteres gerais. Madeira leve, peso específico $0,439 / \mathrm{cm}^{2}$ mole; cor um pouco parda; pouco lustrosa; textura fina; grã irregular; fácil de se trabalhar polindo-se facilmente; cerne indistinto do alburno; casca pouco espessa, com superfície áspera, rica em líquenes, odorífera.

Caracteres macroscópicos (fotos 11 e 16): Poros de distribuição difusa, mas em algumas partes a distribuição é dendrítica, múltiplos e solitários, visiveis com lente $(8 \mathrm{x})$; linhas vasculares distintas, em geral retas, algumas com conteúdo amareiado ou um pouco escuro; parênquima axial moderadamente escasso, pouco distinto; raios não estratificados, distintos a olho desarmado, com trajeto retilíneo: fibras abundantes; camadas fibrosas pouco características; camadas de crescimento distintas, às vezes, descontínuas.

Caracteres microscópicos. Vasos - de distribuição geralmente difusa, às vezes, dendrítica. Poros (foto 12) solitários, geminados e múltiplos agrupados ou radiais, de secção semicircular, semi-ovóide e angulosa; pequenos, $65 \mu \mathrm{m}$ de diâmetro tangencial em média, variando entre 30 e 96 , sendo $70 \%$ entre 59 e 

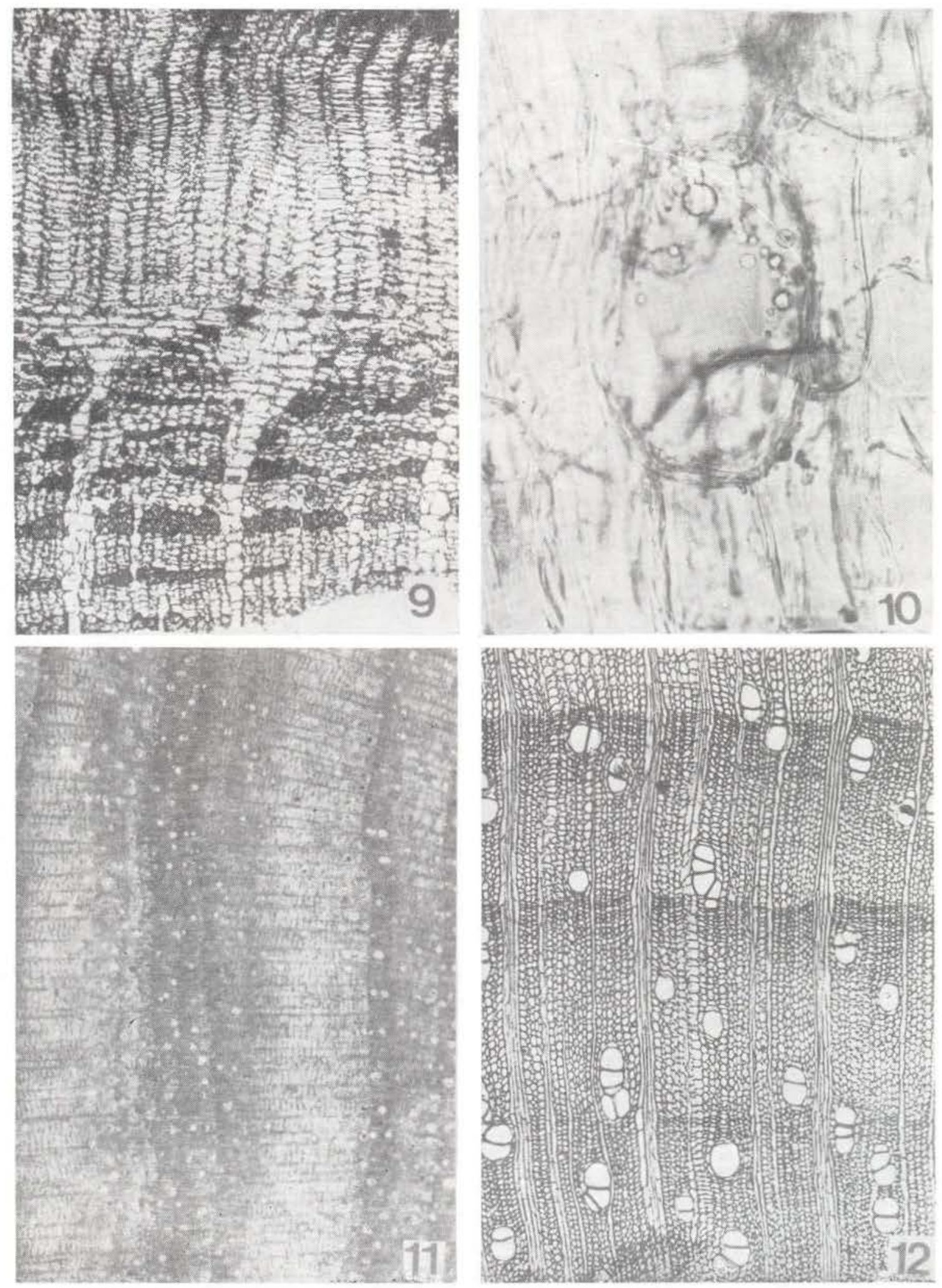

Raiz: Foto 9 - Corte de uma raiz mostrando casca externa e interna (120x); Foto 10 - Glândula secretora com glóbulos lipídicos $(150 \mathrm{x})$. Madeira: Foto 11 - Aspecto macroscópico da madeira (12x); Foto 12 Corte transversal da madeira mostrando camadas de crescimento (80x). 

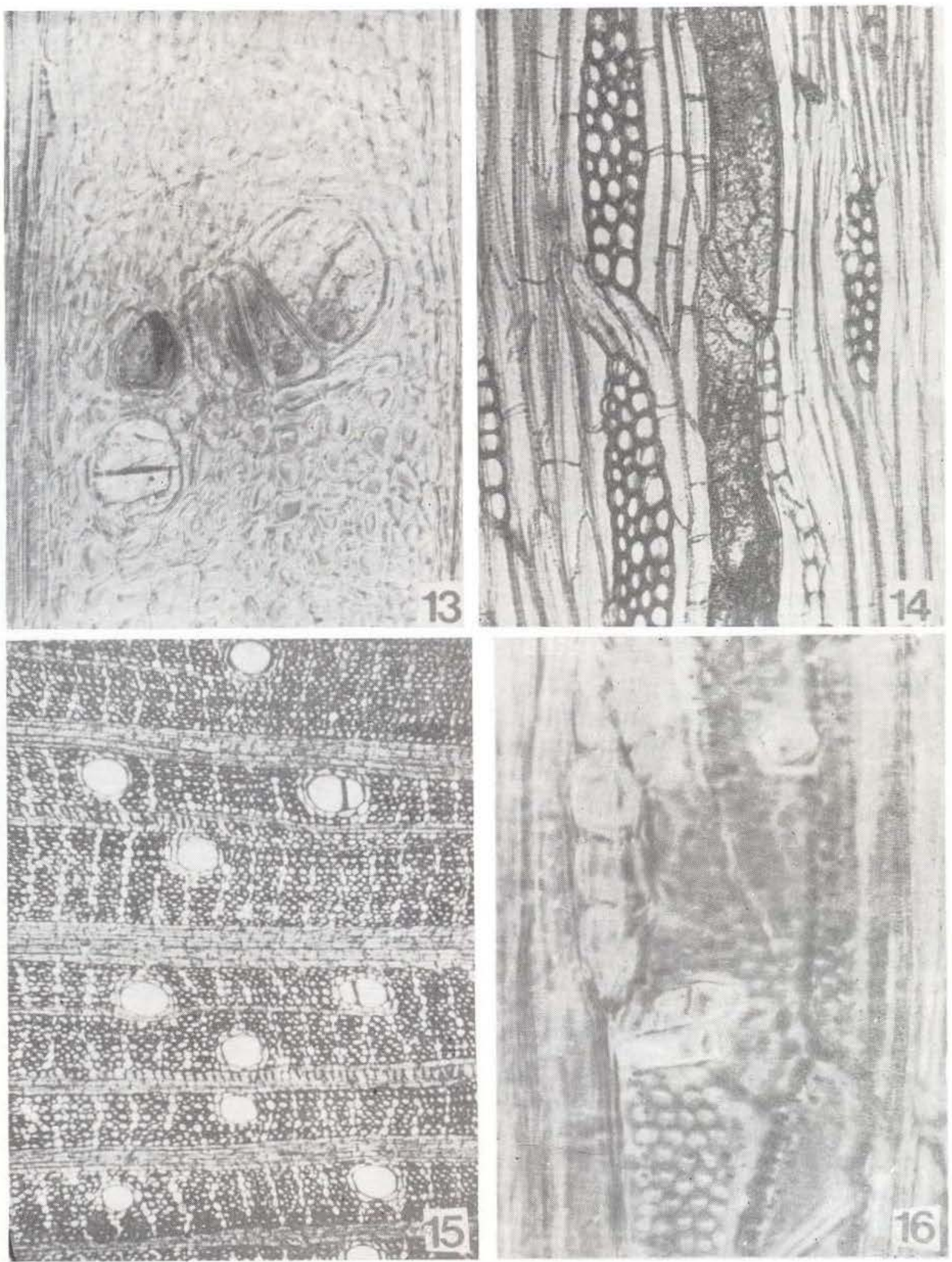

Madeira: Foto 13 - Cortes transversais mostrando poros com silica, ovalato e carbonato (450 e $550 x)$; Foto 14 - Corte tangencial, com elementos mostrando vasos com ŝílica, carbonato e oxalato (250x); Foto 15 - Corte transversal mostrando faixas estreitas de parênquima axial (90x); Foto 16 - Corte tangencıal mostrando elementos de vasos com oxalato (400x). 
82 (pequenos); pouco numerosos, 10 poros por $\mathrm{mm}^{2}$ em média, variando entre 4 e 15, sendo $60 \%$ entre 9 e 12; são freqüentes, no lenho morto, poros cheios de partículas silicosas, acompanhadas de carbonato, e oxalato de cálcio, no mesmo elemento, mas, ocorrem elementos somente com fragmentos silicosos ou com sílica e carbonato ou oxalato de cálcio e sílica ou somente oxalato de cálcio ou carbonato ou oxalato de cálcio e carbonato (fotos $13 \mathrm{e} \mathrm{14}$ ). Elementos vasculares (fotos $14 \mathrm{e}$ 16) em geral com sílica, oxalato de cálcio, e carbonato; curtos, $334 \mu \mathrm{m}$ de comprimento em média, variando entre 284 e 355 (curtos; placa de perfuração simples, total ou parcial, horizontal ou um pouco oblíqua. Pontuações intervasculares pares de montuações areoladas, numerosas, de disposição alterna; pontuações com abertura estreita, inclusa, horizontal. Parênquima axial (foto 15): pouco, apotraqueal, escalariforme, em faixas estreitas e bastante curtas, entre as fibras, de uma camada de células, em geral. Raios (foto 14) homogêneo, tipo II de Kribs, de 1 a 5 seriados, predominando os multisseriados, fusiformes, com as extremidades curtas, às vezes só com uma extremidade afilada, com 3 a 22 células de aıtura, sendo $60 \%$ entre 11 e 14 ; finos, $44 \mu \mathrm{m}$ de largura em média, variando entre 17 e 55 , sendo $55 \%$ entre 33 e 50 ; extremamente baixos, 0,24 $\mathrm{mm}$ de altura em média, variando entre 0,18 e 0,71 , sendo 55 entre 0,27 e 0,35 (extremamente baixos); entre as células radiais ocorrem idioblastos contendo corpos silicosos (foto 17) e outros com cristais de oxalato de cálcio; raios pouco numerosos, entre 4 e 7 por milímetro, raramente 8. Fibras espessas, abundantes, de disposição radial, com pontuações pequenas, areoladas; elementos fibrosos muito curtos, $0,85 \mathrm{~mm}$ de comprimento em média, variando entre 0,58 e 1,75 , sendo $65 \%$ entre 0,69 e $0,92 \mathrm{~mm}$. Nos cortes examinados encontram-se faixas de lenho tardio contrastando-se cō̄ o lenho primaveril (inicial). O limite entre o !enho tardio de uma camada de crescimento e o lenho inicial de outra camada é sinuoso.
Casca - A estrutura anatômica da casca é semelhante a da casca da raiz. Salientamos as pequenas diferenças entre esta e aquela: nesta, o súber e as fibras são mais abundantes, raios mais largos e ocorrem abundantemente idioblastos contendo cristais rômbicos de oxalato de cálcio, na casca viva. Vale a pena salientar que, os referidos idioblastos estão sempre localizados ao longo dos cordões de fibras (foto 18).

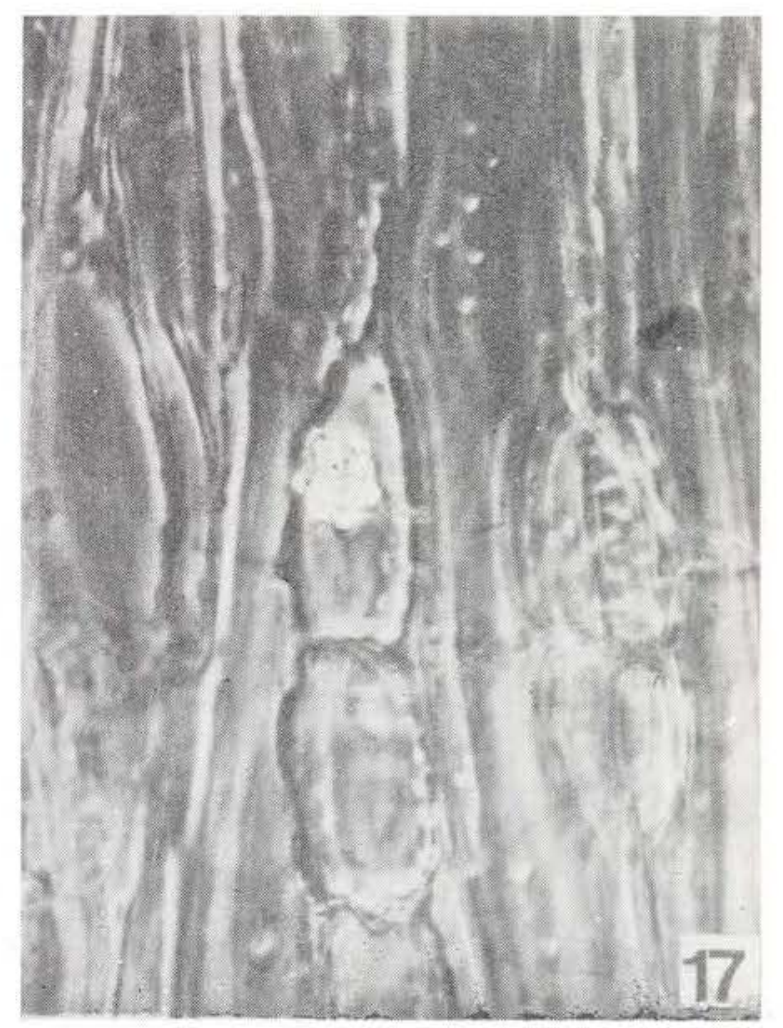

Madeira: Foto 17 - Corte tangencial com sílica no raic (150).

\section{Conclusões}

Raiz - A raiz de Annona glabra L. é extremamente mole, leve esponjosa e semeIhante a cortiça fisicamente; queimando-se com dificuldade; lenho secundário pobre em vasos, fibras ausentes e rica em parênquima axial aerífero, cujas células são pontuadas e semelhantes aos elementos dos vasos; do ponto de vista econômico, poderá substituir a cortiça. A casca contém fibras e óleo essencial. 


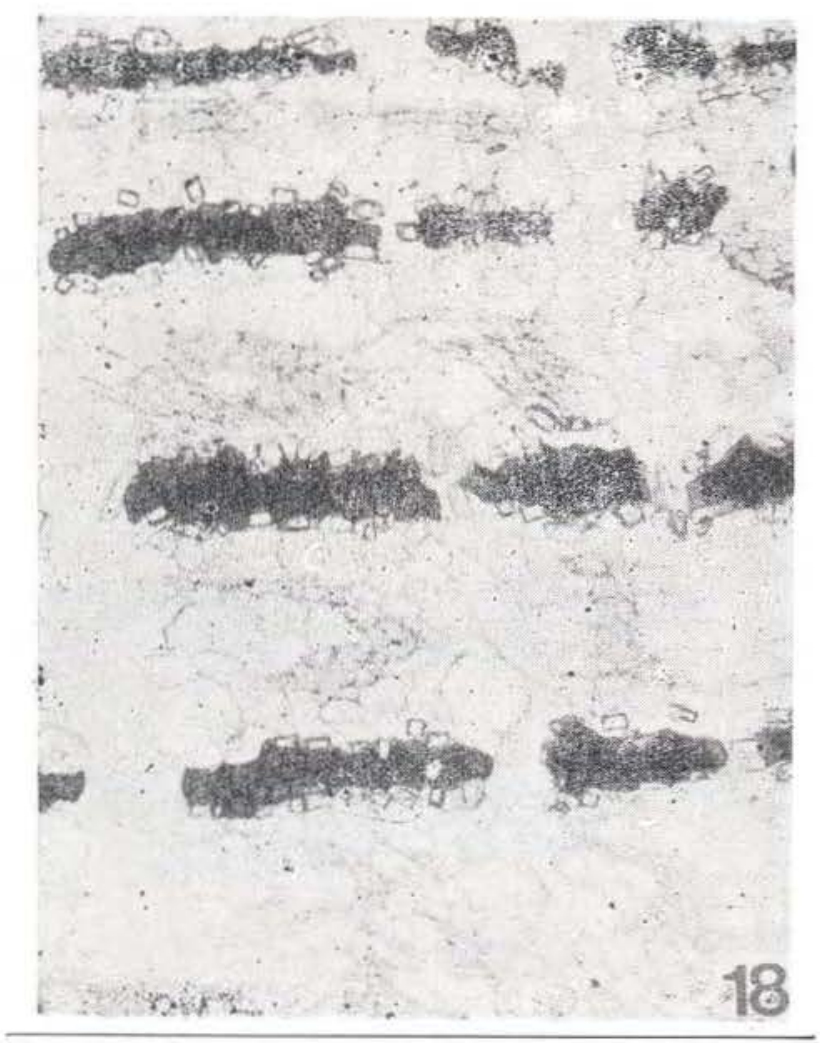

Madeira: Foto 18 - Casca interna com cristais e cordōes de fibras $(120 \mathrm{x})$.

Madeira - Leve e mole; abundância de sílica, carbonato, e oxalato de cálcio, em geral no mesmo elemento de vasos; camadas de crescimento bem caracteristicas; raios homogêneos, tipo II de Kribs. Casca odorifera, rica em cristais rômbicos de oxalato de cálcio. A ortografia do gênero Annona deve ser grafada com $n n$.

\section{Agradecimentos}

Agradecemos ao Dr. Jorge Fontella Pereira, do Jardim Botânico do Rio de Janeiro; Dr. George Eiten, da Universidade de Brasília; e ao Dr. Byron W. Albuquerque, do Instituto Nacional de Pesquisa da Amazônia (INPA).

\section{SUMMARY}

The root of Annona glabra L. is extremely soft, light in weight and spongy, morphologically like cork. The secondary wood has few vessels, no fibers and has a great deal of axial aerenchyma. The aerenchyma celis are pitted and appear like vessel elements.

The bark when cut gives off an abundant volatile perfume. The roots are used by fishemen in Pernambuco (Brazi) and Florida (USA) as floats for their nets.

The wood of the trunk is light weight and soft. In transverse section and in disassociated cells, crystals of silica, calcium carbonate and calcium carbonate and calcium oxalate can be noted, aill in same vessel element. The rays are homogenous of Kribs type II. The bark is perfumed and contains many crystals of calcium oxalate.

The spelling of "Annona" should have two n's because of the origin of the word as used by Linnaeus and also according to the list of Nomina Conservanda.

\section{BIBLICGRAFIA CITADA}

COBLey, L. S.

1957 - The Botany of Tropical crops. New York. 243 p. ilust.

DUCKE, A.

1917 - Plantes nouvelles ou peu connues de la règion amazoonienne. Arq. Jard. Bot., Rio de Janeiro, $2: 28-39$.

ERdtMan, G.

1952 - Pollen morphology and plant taxonomy angiosperms. Stokolm. 239 p. ilust.

FERRI, M. G.

1944 - Transpiração de plantas permanentes dos cerrados. Bol. Fac. Fil. ci. Letr. Univ, São Paulo, I, Botânica, 4 : 159-224, ilust.

FREIRE, C.V.

1943 - Chaves analíticas. 3. ed. Rio de Janeiro. 367 p., ilust.

FrIES, R.E.

1931 - Revision der Arten liniger Anonaceen Gattungen - II. Acta Horti Bergiani, Bruxelas, 10(2): 129-341, 6 fig. $27 \mathrm{p}$.

Ginc, S.

1926 - Botânica aplicada a la farmácia. Barcelona. 322 p., ilust.

Gray, A.

1908 - Manual of Botany. 7. ed. USA, Am. Book co.

HERINGER, E.P.

1955 - Diagnose do fruto de Anona pygmaea. Bol. Soc. Port. Ci. Naturais, Lisboa, 2.a série, V(19):115-118.

Heringer, E.P. \& Barroso, G.M.

1968 - Sucessão das espécies do cerrado em função do fogo, cupim, cultivo e da subsolagem. An. XIX Cong. Nac. Bot., Fortaleza, p. 133-139. 
Hoemne, F.C.; Kuhlmann, J.G. \& Handro, O.

1941 - O Jardim Botânico de São Patilo. Sec. Agr. S. Paulo, $4: 28-49$. ilust.

KuHLMANn, G.

1925 - Contribuição para o conhecimento de algumas plantas novas. Arq. Jard. Bot. Rio de Janeiro, $8: 47-64$.

LOFGREN, A. \& EVERETT

1905 - Sistema analítico de plantas. São Paulo. 184 p., ilust.

LUeTzelBurg, $P$. VAN

1923 - Estudo botânico do Nordeste. In: Inspetoria Federal Obras Contra Secas, Rio de Janeiro, 283 p., ilust.

Metcalfe, C.R. \& Tralk, L.

1957 - Anatomy of dicotyledons. 2v., v.I Lxiv, 724 p., ilust.

MOLISCH, H.

1923 - Mikrochnie der pflanzen. Wien. 438 p.

RECORD, J.S. \& HESS, R.W.

1949 - Tibers of the new world. 640 p., ilust.
RIZZINI, C.T.

1963 - A flora do cerrado. In: Simpósio sobre

o cerrado, São Paulo, p. 127-177.

SANTOS, J.G.

1963 - Nomes vernáculos de algumas plantas da Guiné Portuguesa. Inst. Inves. U1tramar., Lisboa.

SOUZA, E.P. DE

1960 - Estudos, ensaios e documentos, Lisboa, 24 : 42-86, ilust.

SCHULTZ, A.R.

1963 - Introdução ao estudo da Botânica sistemática. Porto Alegre, Globo, 477 p. ilust.

Stafleu, F.A. et al.

1962 - International Code of Botanical Nomenclature. Utrecht. $115 \mathrm{p}$. 